\title{
The Use of Rice Hulls for Sustainable Control of NOx Emissions
} in Deep Space Missions

\author{
X. H. Xu' ${ }^{\circ}$ Y. Shi ${ }^{\circ}$, and S.G. Chang* \\ Environmental Energy Technology Division \\ Lawrence Berkeley National Laboratory \\ Berkeley, CA 94720
}

J. W. Fisher, S. Pisharody, M. J. Moran, and K. Wignarajah

Astrobiology Technology Branch

NASA Ames Research Center

Moffett Field, CA 94035

\begin{abstract}
The use of the activated carbon produced from rice hulls to control NOx emissions for the future deep space missions has been demonstrated. The optimal carbonization temperature range was found to be between $600^{\circ} \mathrm{C}$ and $750^{\circ} \mathrm{C}$. The burnoff of $61.8 \%$ was found at $700^{\circ} \mathrm{C}$ in pyrolysis and $750^{\circ} \mathrm{C}$ in activation. The BET surface area of the activated carbon from rice hulls was determined to be $172 \mathrm{~m}^{2} / \mathrm{g}$ when prepared at $700^{\circ} \mathrm{C}$. The presence of oxygen in flue gas is essential for effective adsorption of NO by the activated carbon. On the contrary, water vapor inhibits the adsorption efficiency of NO. Consequently, water vapor in flue gas should be removed by drying agents before adsorption to ensure high $\mathrm{NO}$ adsorption efficiency. All of NO in the flue gas was removed for more than one and a half hours when $10 \%$ oxygen was present and using a ratio of the carbon weight to the flue gas flow rate $(\mathrm{W} / \mathrm{F})$ of $15.4 \mathrm{~g}-\mathrm{min} / \mathrm{L}$. The reduction of the adsorbed $\mathrm{NO}$ to form $\mathrm{N}_{2}$ can be effectively accomplished under anaerobic conditions at $550^{\circ} \mathrm{C}$. For NO saturated activated carbon, the loss of carbon mass was determined to be about $0.16 \%$ of the activated carbon per cycle of regeneration. The reduction of the adsorbed $\mathrm{NO}$ also regenerates the activated carbon. The regenerated activated carbon exhibits improved NO adsorption efficiency.
\end{abstract}

\section{Introduction}

Human space travel depends upon the operation of life support systems. In deep space missions, such as the mission to Mars, life support cannot depend upon storage alone, it requires a fully regenerative system as well, i.e. waste must be reclaimed for reuse.

A number of solid waste reclamation technologies are under investigation for space applications (Fisher et.al., 1998). Technologies such as incineration, supercritical water oxidation, steam reformation, and electrochemical oxidation are at various stages of

* Corresponding author. Email: sgchang@lbl.gov; Fax: 510-486-7303

${ }^{\circ}$ On leave from the Environmental Engineering Department, Zhejiang University, Hangzhou, China. 
development for use in space. Incineration is perhaps the most promising technology because it rapidly and completely converts the waste to carbon dioxide, water, and minerals. Incineration also lends itself to experiment more affordably than most of the other technologies, and it is already the most thoroughly developed technology for use in a terrestrial environment. The major difficulty with the use of incineration, particularly in a closed environment, is the emission of pollutants that can build up, thus necessitating a flue gas cleanup system.

Incineration of the inedible portion of crops and wastes, such as human feces, produces mostly carbon dioxide, water, and ash. However the incineration also produces NOx and $\mathrm{SO}_{2}$; pollutants that need to be removed from flue gas and recovered for reuse. NOx is produced from nitrogen in the waste or fuel and from the nitrogen in the air. Similarly, the sulfur in the waste is converted to $\mathrm{SO}_{2}$ during incineration.

To conserve the nutrients for life support, NOx should be converted to $\mathrm{N}_{2}, \mathrm{NH}_{3}$, and/or nitrates. The $\mathrm{N}_{2}$ can be used to replace cabin $\mathrm{N}_{2}$ leakage and/or the loss of $\mathrm{N}_{2}$ during combustion, while $\mathrm{NH}_{3}$ and nitrates can be recycled as part of the plant hydroponics nutrient solution. The $\mathrm{SO}_{2}$ can be converted to either elemental sulfur or sulfate because elemental sulfur can be safely stored or converted to sulfate, where sulfate can be recycled as part of the plant hydroponics nutrient solution as well.

Many flue-gas clean up technologies have been developed to remove $\mathrm{NOx}$ and $\mathrm{SO}_{2}$ from terrestrial incineration (Sada et. al., 1980; Martin, A.E., 1981; Tsai et. al., 1989). Most of the technologies require expendables, making them unsuitable for a space application. Processes that use catalyst (Jin et. al., 1997; Yu et. al. 1997) may have problems because catalyst poisoning is an issue that limits the life-span of a catalyst. The poisoning of the catalyst by soot, alkali metals, and chlorides in the flue gases can occur, and wet processes (Chang and Liu, 1990; Chang and Lee, 1992; Pham and Chang, 1994; Shi et. al., 1996) that handle liquids, like using spray absorbers, pose difficulty because of the micro-gravity situation. What also need to be addressed are the issue of safety and energy requirements of the technology. Using potential hazardous high-pressure systems and/or systems that require an excessive amount of electric energy is unwarranted for space missions.

In view of the aforementioned constraints and requirements, we are investigating an approach involving the use of rice hulls, an inedible biomass that can be continuously produced in a space vehicle, to clean up flue gas pollutants generated during incineration. We have found that flue gas from the incineration of biomass contains an insignificant amount of $\mathrm{SO}_{2}$, and that most of the sulfur in the biomass has ended up as sulfate in flyash. Presumably, $\mathrm{SO}_{2}$ has reacted with the alkali metal in the biomass, thus, this study focuses on the control of NOx emissions. The approach involves the carbonization of the rice hulls to produce activated carbon for the adsorption of NOx and a subsequent reduction of the adsorbed NOx by carbon to $\mathrm{N}_{2}$. The optimal conditions for the production of activated carbon from rice hulls for the adsorption of NOx has been determined. Parametric studies on the adsorption of NOx by the carbon have been 
performed. The effectiveness of this approach to control NOx emissions in deep space missions has also been assessed.

\section{Experimental Section}

Materials. The following materials were used: $\mathrm{NO}\left(5 \%\right.$ with $\mathrm{N}_{2}$ as balance, Scott Co.), standard NO (500ppm with $\mathrm{N}_{2}$ as balance, Scott Co.), $\mathrm{CO}_{2}, \mathrm{~N}_{2}, \mathrm{O}_{2}$ (Airgas Co.), and rice hulls (field grown).

Experimental Setup. A schematic diagram of the experimental set-up used for the preparation of char from inedible biomass, the adsorption of NOx on a char bed, and the reduction of NOx by carbon at elevated temperatures to form $\mathrm{N}_{2}$, is shown in Fig. 1. The main component of the system is a 2" I.D. for char preparation, which is switched to a 3/4" I.D. stainless steel tube (all 30" length) reactor for adsorption, de-adsorption and regeneration. The tubular reactors are put into a tube furnace (Thermolyne, Type F121100) for heating. The furnace has the function of running an automatic set point ramping program.

Preparation of Carbon. Approximately $55.0 \mathrm{~g}$ of rice hull was tightly packed into a cylinder for activation. Nitrogen and Carbon dioxide were used as the pyrolysis and activation gases, respectively. The gas flow rate for pyrolysis was 0.5-1.0 L nitrogen per minute and activation was $0.25 \mathrm{~L}$ carbon dioxide per minute. Pyrolysis and activation times (between $0.5 \mathrm{hr}$ and $6 \mathrm{hr}$ ), and temperatures (between $300^{\circ} \mathrm{C}$ and $950^{\circ} \mathrm{C}$ ) were varied during carbonization in order to obtain optimal activation conditions. The activation temperature was usually $50^{\circ} \mathrm{C}$ higher than the pyrolysis temperature. The notation of the activated carbon "RH-2-600-1-650" implies that the activated carbon was prepared from rice hulls with a $2 \mathrm{hrs}$ pyrolysis time at $600^{\circ} \mathrm{C}$ followed by $1 \mathrm{hr}$ of activation at $650^{\circ} \mathrm{C}$. Once activation was complete, $\mathrm{CO}_{2}$ was supplied to the sample until it could be sealed in a container.

Characterization. Specific surface areas of samples were determined by gas adsorption using an automated adsorption apparatus (Micromeritics, ASAP 2010). Nitrogen adsorption/desorption was measured isothermally at $-196^{\circ} \mathrm{C}$. Before any such analysis, the sample was degassed at $250^{\circ} \mathrm{C}$ in a vacuum to about $10^{-3}$ torr. The Nitrogen isotherms were analyzed by the BET equation to determine the surface area of the char. BJH adsorption cumulative pore size of the sample was also determined.

Adsorption. Most of $\mathrm{NOx}$ in flue gas from combustion is in the form of NO. Also, $\mathrm{NO}_{2}$ is readily adsorbed on the activated carbon. Consequently, efforts were directed to determine conditions for maximal removal efficiency of NO. Experiments were conducted to evaluate the effects of carbon preparation conditions, adsorption temperatures, flue gas flow rate, and the concentrations of oxygen, water vapor, and NO on the adsorption efficiency of NO. The experimental system simulated flue gas with variable concentrations of $\mathrm{N}_{2}$, carbon dioxide, oxygen, $\mathrm{NO}$, and $\mathrm{H}_{2} \mathrm{O}$. The gas flow rate varied from $250-1500 \mathrm{ml} / \mathrm{min}$. The sample was heated at a $40^{\circ} \mathrm{C} / \mathrm{min}$ gradient from room temperature to the heat-treatment temperature desired. 
$\mathrm{NO}$ and $\mathrm{NO}_{2}$ concentrations were analyzed by a chemiluminescent $\mathrm{NO}-\mathrm{NO}_{2}-\mathrm{NOx}$ analyzer (ThermoElectron Co., Model 14A). The amount of NOx adsorbed by the activated carbon was determined from the difference in NOx concentration of the inlet and outlet gases. It was assumed that the missing NOx was adsorbed by the activated carbon. Some reactions were repeated at least twice to examine reproducibility.

Reduction and Regeneration. Reduction of $\mathrm{NO}$ and regeneration of the activated carbon were accomplished by heating the NO loaded char in the absence of oxygen. In order to evaluate the behavior of the process over time, a purge gas flow of nitrogen was applied during experiments, whose outlet was directed to a gas analyzer. The sample was then heated from room temperature to $600^{\circ} \mathrm{C}$ at a $40^{\circ} \mathrm{C} / \mathrm{min}$ gradient. The gas flow rate for de-sorption and regeneration was $1.0 \mathrm{~L}$ nitrogen per minute.

Space Maximum Allowable Concentration. The space maximum allowable concentration (SMAC) of NO in a human occupied cabin is $4.8 \mathrm{ppm}$, and thus reduced NO concentrations to the level of SMAC can serve as an indicator for meeting the requirement. Experiments were conducted at room temperature using rice hulls activated carbon (RH-2-700-1-750). The principle variables manipulated were inlet of oxygen concentration and the ratio of weight to flow rate, W/F, (W: weight of the activated carbon in $\mathrm{g}$. and $\mathrm{F}$ : flow rate of flue gas in $\mathrm{L} / \mathrm{min}$ ) in order to determine the conditions to keep outlet NO concentrations below SMAC. Inlet gas concentrations were controlled by varying gas flow rates. Oxygen concentration ranged from $5 \%$ to $20 \%$ and $\mathrm{W} / \mathrm{F}$ ranged from 15 to $45 \mathrm{~g} \cdot \mathrm{min} / \mathrm{L}$.

\section{Results and Discussion}

\section{Preparation and Characterization of Activated Carbon}

Burnoff. In order to determine optimal carbonization temperatures, rice hull samples were heated between $300^{\circ} \mathrm{C}$ and $900^{\circ} \mathrm{C}$ for two hours in pyrolysis and between $350^{\circ} \mathrm{C}$ and $950^{\circ} \mathrm{C}$ for one hour in activation, the temperature of activation being $50^{\circ} \mathrm{C}$ higher than that of pyrolysis. Afterwards, percent burnoff was measured. Higher carbonization temperatures caused larger portions of the samples to burn off and turn to ash, leading to greater amounts of material to be lost, as shown in Fig.2. About 75.6\% of the rice hull sample burned off when temperatures were kept at $900^{\circ} \mathrm{C}$ in pyrolysis and $950^{\circ} \mathrm{C}$ in activation, while just $61.8 \%$ burnoff was recorded at $700^{\circ} \mathrm{C}$ in pyrolysis and $750^{\circ} \mathrm{C}$ in activation. To prevent significant burnoff and ash generation, it is recommended that reactions not be run at temperatures exceeding $750^{\circ} \mathrm{C}$.

Surface Area and Cumulative Pore Area. The activated carbons were characterized by the measurement of their average pore size and surface area. There are three types of pores which developed in the solid: micropores $(<2 \mathrm{~nm})$, mesopores $(2-50 \mathrm{~nm})$, and macropores $(>50 \mathrm{~nm})$. The average pore size has an effect on the total surface area that is available for adsorption. The BET surface area and BJH average pore size of activated carbon prepared from rice hulls $(\mathrm{RH})$ under different conditions were measured. Temperature and hold time used for activation was varied. As the temperatures varied from $350^{\circ} \mathrm{C}$ to $800^{\circ} \mathrm{C}$ and the activation time from $0.5 \mathrm{hr}$ to $5 \mathrm{hrs}$, the BET and $\mathrm{BJH}$ of 
activated carbon from rice hulls ranged from $76.5 \mathrm{~m}^{2} / \mathrm{g}$ to $172.9 \mathrm{~m}^{2} / \mathrm{g}$ and from 25.1 to 67.1 A, respectively. In general, the BET increases with the increase of temperature until about $700^{\circ} \mathrm{C}$. Further increases of temperature results in decreases of BET surface area. The BET of rice hulls activated carbon was $76.5 \mathrm{~m}^{2} / \mathrm{g}, 167.1 \mathrm{~m}^{2} / \mathrm{g}, 172.9 \mathrm{~m}^{2} / \mathrm{g}$, and 147.9 $\mathrm{m}^{2} / \mathrm{g}$ with an activation temperature of $350^{\circ} \mathrm{C}, 600^{\circ} \mathrm{C}, 700^{\circ} \mathrm{C}$, and $800^{\circ} \mathrm{C}$, respectively. The time used for activation did not affect the BET surface area substantially under the conditions $(0.5 \mathrm{hr}-2 \mathrm{hrs})$ employed. The BJH average pore size initially increases with the increase in time, but decreases with prolonged activation. Prolonged activation results in an increase in burnoff. The $\mathrm{BJH}$ average pore size of rice hulls char activated at $600^{\circ} \mathrm{C}$ was $25.1 \mathrm{~A}, 67.1 \mathrm{~A}$, and $45.1 \mathrm{~A}$ with an activation time of $0.5 \mathrm{hr}, 1.0 \mathrm{hr}$, and $2 \mathrm{hr}$, respectively.

It is imperative that the larger the BET surface area and the larger the BJH cumulative pore areas, the higher the adsorption efficiencies must be. Typical BJH adsorption cumulative pore areas for different samples are shown in Fig.3. From the graph, it can be inferred that activated carbon made from rice hulls has a large $\mathrm{BJH}$ adsorption cumulative pore area, close to that of coconut shell (commercial products), but significantly larger than two other biomass (wheat straw and peanut shells) samples shown. Because of the superior surface area and average pore size measured for rice hulls activated carbon than those of wheat straw and peanut shells, this study concentrates on rice hulls carbon.

Determining Optimal Temperature and Time for Carbon Preparation. Optimal pyrolysis and activation temperatures and times for carbon preparation were determined based on the amount of NOx that can be adsorbed by the activated carbon. The adsorption capacities of rice hull activated carbons generated by different pyrolysis and activation temperatures are shown in Fig.4. A simulated flue gas containing $250 \mathrm{ppm}$ $\mathrm{NO}, 5 \% \mathrm{O}_{2}, 10 \% \mathrm{CO}_{2}$, with $\mathrm{N}_{2}$ as the balance was passed through the tubular reactor containing $2 \mathrm{~g}$ of activated carbons at a flow rate of $250 \mathrm{ml} / \mathrm{min}(\mathrm{W} / \mathrm{F}=8 \mathrm{~g} \cdot \mathrm{min} / \mathrm{L})$ at $25^{\circ} \mathrm{C}$. It is evident from the plots that the NO removal efficiency increases in the order of RH-2300-1-350, RH-2-400-2-450, RH-2-500-1-550, RH-2-600-1-650, RH-2-700-1-750, and RH-2-800-1-850. Activated carbon derived from the highest tested pyrolysis and activation temperatures exhibited the best adsorption efficiency. The better adsorption efficiency is attributed to higher microporosity obtained at higher carbonization temperatures. But samples carbonized above $700^{\circ} \mathrm{C}$ have a higher burnoff rate than those carbonized at lower temperatures. In order to obtain a better production yield of activated carbon, $700^{\circ} \mathrm{C}$ and $750^{\circ} \mathrm{C}$ for pyrolysis and activation, respectively are chosen as optimum for the preparation of rice hull activated carbon.

The NO adsorption efficiencies of samples carbonized by differing pyrolysis and activation times are shown in Figure 5. It is evident from the plots that activated carbons carbonized by prolonged pyrolysis and activation times have better adsorption efficiencies than those carbonized by shorter times due to higher pore count and BET surface area. It can be seen from these figures that the micropore count and the surface area of activated carbon increases with longer preparation time, thus explaining why the 
samples with the longest pyrolysis and activation times have the best adsorption efficiencies. However, prolong activation results in more burnoff and the production of ash. A balance must be reached when setting reaction parameters; one that will generate the largest surface area without a significant burnoff. We found that the optimal pyrolysis and activation times are two and one hour, respectively.

\section{Parametric Study of the Removal Efficiency of NO}

Temperature Effects on Adsorption. The removal efficiency of $\mathrm{NO}$ by carbon was studied at various temperatures: $10^{\circ} \mathrm{C}, 100^{\circ} \mathrm{C}, 300^{\circ} \mathrm{C}, 400^{\circ} \mathrm{C}$, and $500^{\circ} \mathrm{C}$. A gas mixture containing $250 \mathrm{ppm} \mathrm{NO}$ in $\mathrm{N}_{2}$ was passed through a column of carbon with a W/F of 15.4 g-min/L. Fig. 6 shows that NO removal efficiency decreases with increased temperatures, when kept below $100^{\circ} \mathrm{C}$. However, further increases in temperature beyond $100^{\circ} \mathrm{C}$ reversed the course, causing an increase in NO removal efficiency. This phenomenon is attributed to the reduction of NO by activated carbon, which results in the formation of nitrogen gas.

The results from this set of experiments indicate that at the condition of $\mathrm{W} / \mathrm{F}$ employed, $\mathrm{NO}$ can be completed reduced to $\mathrm{N}_{2}$ at temperatures equal to or above $500^{\circ} \mathrm{C}$, while only some of the inlet $\mathrm{NO}$ is reduced to $\mathrm{N}_{2}$ at temperature below $500^{\circ} \mathrm{C}$. The fraction of $\mathrm{NO}$ converted to $\mathrm{N}_{2}$ increases with the increase of reaction temperatures.

Oxygen Effects on Adsorption. Six experiments using 0\%, 0.5\%, 1\%, 3\%, 5\%, and $10 \% \mathrm{O}_{2}$ were performed at room temperature. Fig. 7 shows that when $10 \%$ oxygen is present, all of NO in the flue gas was removed for more than one and half hours, and that $98.7 \%$ of NO was removed even after $2 \mathrm{hrs}$ by using a W/F of $15.4 \mathrm{~g}-\mathrm{min} / \mathrm{L}$. As can be seen from Fig 6, NO removal efficiency decreases along with decreases in $\mathrm{O}_{2}$ concentration in the flue gas. Only about $10 \%$ of inlet NO was removed after $2 \mathrm{hrs}$ in the absence of oxygen. It is obvious that the presence of oxygen is critical for the NO adsorption by carbon to be effective. This phenomenon is attributed to the catalytic oxidation of $\mathrm{NO}$ by $\mathrm{O}_{2}$ on the carbon surface to form $\mathrm{NO}_{2}$, which is more readily adsorbed by the activated carbon.

Moisture Effects on Adsorption. It is expected that the high temperature flue gas will be cooled down before passing to the carbon bed to avoid the combustion of carbon due to the presence of flue gas oxygen. This cooling down results in the condensation of water vapor. Flue gas can contain up to $3.0 \% \mathrm{v} / \mathrm{v} \mathrm{H}_{2} \mathrm{O}$ even after cooling down to room temperature, thus it is important to study the effect of water vapor on the removal efficiency of NO by carbon. Fig. 8 shows that moisture causes a significant decrease in NO removal efficiency by carbon. The more water vapor present in the flue gas, the lower the NO removal efficiency exhibited. This is due to the fact that water vapor competes effectively with NO for the adsorption sites on carbon particles. The detrimental effect of water vapor on NO adsorption can be overcome by the removal of water vapor either by drying agents or by cooling flue gas to low temperatures prior to adsorption. 
Flow Rate Effect on Adsorption. The effect of flue gas flow rate on the NO removal efficiency of a given amount of carbon was studied. A simulated flue gas with a composition of 250 ppm NO, $5 \% \mathrm{O}_{2}, 2 \% \mathrm{H}_{2} \mathrm{O}, 10 \% \mathrm{CO}_{2}$ with $\mathrm{N}_{2}$ as the balance was passed through a column of $15.3 \mathrm{~g}$. carbon at $25^{\circ} \mathrm{C}$. Fig.9 illustrates adsorption profiles of $\mathrm{NO}$ by rice hull activated carbon at five different flow rates. The NO removal efficiency after $2 \mathrm{hrs}$ was $84 \%, 68 \%, 48 \%, 42 \%$, and $36 \%$ with a flow rate of $250 \mathrm{ml} / \mathrm{min}$, $500 \mathrm{ml} / \mathrm{min}, 750 \mathrm{ml} / \mathrm{min}, 1000 \mathrm{ml} / \mathrm{min}$, and $1500 \mathrm{ml} / \mathrm{min}$, respectively. As would be expected, smaller flow rates favor the NO removal efficiency as the adsorption time is longer compared to that of larger flow rates.

\section{Reduction of NO by Activated Carbon}

The adsorbed NO can be desorbed from activated carbon if temperature of the carbon bed is raised. Further increases of temperature results in the reduction of NO by activated carbon to produce $\mathrm{N}_{2}$. Simultaneously, the activated carbon is regenerated as a result of the reduction of $\mathrm{NO}$ to $\mathrm{N}_{2}$.

Experiments on the reduction of the adsorbed NO by the activated carbon were performed by heating the NO saturated carbon under anaerobic conditions. In order to evaluate the behavior of the process over time, a purge gas flow of $1.0 \mathrm{~L} / \mathrm{min} \mathrm{N}_{2}$ was passed through the carbon bed and subsequently directed to the NOx analyzer. Desorption was conducted with a temperature ramp rate of $40^{\circ} \mathrm{C} / \mathrm{min}$ from room temperature to $600^{\circ} \mathrm{C}$. As the temperature of the carbon bed was increased, NO was desorbed from the surface of the activated carbon. Further increase of the temperature results in the reduction of $\mathrm{NO}$ by the activated carbon to $\mathrm{N}_{2}$. The fraction of the adsorbed NO that is reduced to $\mathrm{N}_{2}$ can be calculated by subtracting the NO coming out of the carbon bed from the total amount of NO adsorbed. The fraction of the adsorbed NO that is reduced depends on the temperature and the flow rate of $\mathrm{N}_{2}$ gas.

Fig.10 shows the fraction of the desorbed NO integrated over the temperatures as the temperatures of the carbon bed was raised. As can be seen, the fraction of the total $\mathrm{NO}$ desorbed as $\mathrm{NO}$ reaches the maximum at $550^{\circ} \mathrm{C}$ and that this fraction was less than $100 \%$ of the total $\mathrm{NO}$ adsorbed, the difference of which being attributed to the reaction of $\mathrm{NO}$ with the activated carbon to form $\mathrm{N}_{2}$. The fraction of the adsorbed $\mathrm{NO}$ desorbed as $\mathrm{NO}$ is $48.2 \%$ in the case when $\mathrm{NO}$ adsorption was done without the presence of $\mathrm{H}_{2} \mathrm{O}$ vapor, and $64.5 \%$ in the case when $\mathrm{NO}$ adsorption was performed with $2 \% \mathrm{H}_{2} \mathrm{O}$. This result indicates that NO reduction by activated carbon is inhibited by the presence of water vapor. Water vapor can compete with $\mathrm{NO}$ for the reaction with activated carbon. From the desorption curve as a function of temperature, the NO desorption mainly took place at temperature below $300^{\circ} \mathrm{C}$, while the NO reduction by carbon occurred at temperature above $300^{\circ} \mathrm{C}$, the higher the temperature the more effective the reduction is. Since the ramp rate was $40^{\circ} \mathrm{C}$ per min., it would take 7.5 minutes to raise from $300^{\circ} \mathrm{C}$ to $600^{\circ} \mathrm{C}$, the temperature range when most of the NO reduction takes place. During the $7.5 \mathrm{~min}$. time interval, about $50 \%$ of the adsorbed NO was reduced to $\mathrm{N}_{2}$. Consequently, it can be 
concluded that the complete reduction of $\mathrm{NO}$ to $\mathrm{N}_{2}$ at $550^{\circ} \mathrm{C}$ can be done within 15 minutes in a closed system.

Another set of experiments were performed to study the reduction of NO by activated carbon as a function of temperature and $\mathrm{W} / \mathrm{F}$, the ratio of the amount of carbon to flow rate of $\mathrm{N}_{2}$. In this study, temperatures were varied between 300 and $550^{\circ} \mathrm{C}$ and $\mathrm{W} / \mathrm{F}$ between 10 and 40 g.min/L. Fig. 11 shows that with a feed gas containing $250 \mathrm{ppm} \mathrm{NO}$ with the balance $\mathrm{N}_{2}$, the fraction of NO reduced by activated carbon increases with the increase of temperature at a given $\mathrm{W} / \mathrm{F}$, and the fraction also increases with the increase of $\mathrm{W} / \mathrm{F}$ at a given temperature. All of $\mathrm{NO}$ was reduced to $\mathrm{N}_{2}$ at $550^{\circ} \mathrm{C}$ with a $\mathrm{W} / \mathrm{F}$ above 20 g.min/L, and at $500^{\circ} \mathrm{C}$ with a W/F 40 g.min/L. It would require a W/F larger than 40 g.min/L to convert all of $\mathrm{NO}$ to $\mathrm{N}_{2}$ at temperature below $500 \mathrm{C}$.

The NO reduction efficiency also depends on the concentration of NO in the system. Fig 12 shows $\mathrm{NO}$ reduction at $500^{\circ} \mathrm{C}$ for two inlet $\mathrm{NO}$ concentrations, $250 \mathrm{ppm}$ and 1000 ppm. As can be seen, higher inlet NO concentrations cause less fraction of NO to be reduced. Only $55 \%$ of inlet $\mathrm{NO}$ was reduced at $500^{\circ} \mathrm{C}$ with an inlet $\mathrm{NO}$ concentration of $1000 \mathrm{ppm}$ and a W/F of 40g.min.L-1.

\section{Space Maximum Allowable Concentration (SMAC) of NO}

Experiments were conducted at room temperature using rice hull activated carbon (RH-2700-1-750) to determine at what conditions it would prolong efficient adsorption of NO and that outlet concentrations would be less than SMAC (4.8 ppm). The principle variables manipulated were inlet oxygen concentration, ranging from $5 \%$ to $20 \%$, and weight to flow rate ratio $(\mathrm{W} / \mathrm{F})$, ranging from 15 to $45 \mathrm{~g} \cdot \mathrm{min} / \mathrm{L}(\mathrm{W} / \mathrm{F})$. The time that the carbon bed can hold before the NOx concentration exiting the bed exceeds the SMAC, will be called SMAC time.

Fig.13 shows SMAC time at different oxygen concentrations. The SMAC time increases along with increases in $\mathrm{O}_{2}$ concentrations. The SMAC time was longer than 6 hours with oxygen concentration of $10 \%$ and $\mathrm{W} / \mathrm{F}$ of $45 \mathrm{~g} \cdot \mathrm{min} / \mathrm{L}$, while about 10 hours were obtained with an $15 \%$ oxygen and W/F of $45 \mathrm{~g}$.min/L. As previously mentioned, oxygen presence enhances $\mathrm{NO}$ adsorption, thus allowing the SMAC time to be longer. Increasing $\mathrm{W} / \mathrm{F}$, especially above $20 \mathrm{~g} \cdot \mathrm{min} / \mathrm{L}$, also increases the SMAC time.

Experiments were conducted to determine the effects of the regeneration on activated carbon in terms of NO removal efficiency, as assessed by the carbon's SMAC time. Fig.14 shows the SMAC time after different numbers of regeneration cycles. The results indicate that regeneration improves the removal efficiency of NO. This phenomenon is attributed to the increase of surface area and micropores of the activated carbon. However, it was observed that additional carbon burns off occurs during regeneration, which causes the overall amount of activated carbon to decrease after each regeneration cycle.

The loss of mass was determined to be about $0.16 \%$ of activated carbon per cycle of regeneration. The SMAC time was 163 minutes and 372 minutes for the first and the 8th 
cycle run, respectively. The larger the activated carbon adsorption efficiency, the longer the SMAC time will be.

\section{Conclusion}

Commercial activated carbon, made mostly from materials such as coconut shells and coal, has been studied for the adsorption and/or reduction of $\mathrm{NOx}$ and $\mathrm{SO}_{2}$ (Kaneko et. al., 1988; Lu and Do, 1991; Tsuji et.al., 1991; Illan-Gomez et.al., 1993; Yougen and Cha, 1996). In this study, we have demonstrated that rice hulls, an inedible by-product of crop that may be grown in space vehicles, can be converted to the activated carbon for the adsorption and reduction of $\mathrm{NO}$ in an effective manner. No expendable material, such as binders, is needed for making an effective activated carbon. After the saturation of the adsorbed NOx, the activated carbon can be regenerated for reuse. The regeneration can be simply done by heating the carbon bed under anaerobic conditions to about $550^{\circ} \mathrm{C}$, when the adsorbed NOx is reduced to $\mathrm{N}_{2}$. The regenerated activated carbon exhibits improved $\mathrm{NO}$ adsorption efficiency.

The optimal carbonization temperature of rice hulls was found to be around $700^{\circ} \mathrm{C}$ when the burnoff was $62 \%$. The BET surface area of the activated carbon was determined to be $172 \mathrm{~m}^{2} / \mathrm{g}$. Higher carbonization temperatures caused larger portions of the rice hulls to burn off and turn to ash. The presence of oxygen in flue gas is necessary for an effective adsorption of NO by the activated carbon. On the contrary, water vapor inhibits the adsorption efficiency of NO. Consequently, water vapor in flue gas should be removed either by condensation at low temperatures or by drying agents before adsorption to ensure high $\mathrm{NO}$ adsorption efficiency. All of NO in the flue gas was removed for more than one and a half hours when $10 \%$ oxygen was present and using a ratio of the carbon weight to the flue gas flow rate (W/F) of $15.4 \mathrm{~g}-\mathrm{min} / \mathrm{L}$. For NO saturated activated carbon, the loss of carbon mass was determined to be about $0.16 \%$ of the activated carbon per cycle of regeneration.

\section{Acknowledgements}

This work was supported by the U.S. NASA Life Support Program and the Assistant Secretary for Fossil Energy, U.S. Department of Energy, under Contract DE-AC0376SF00098 through the National Energy Technology Laboratory. 


\section{References}

Chang, S.G.; Liu, D.K. Removal of Nitrogen and Sulphur Oxides from Waste Gas Using a Phosphorus/Alkali Emulsion, Nature 1990, 343, 151-153.

Chang, S.G.; Lee, G.C. LBL PhoSNOX Process for Combined Removal of $\mathrm{SO}_{2}$ and NOx from Flue Gas. Environ. Progr. 1992, 11, 66-73.

Fisher, J.W.; Pisharody, S.; Wignarajah, K.; Lighty, J. S.; Burton, B.; Edeen, M.; Davis, K. S. Waste Incineration for Resource Recovery in Bioregenerative Life Support Systems. Technical Paper No. 981758, Proceedings of the 28th International Conference on Environmental Systems, 1998.

Illan-Gomez, M.J.; Linares-Salano, A.; Salinas-Martinez de Lecea, C. NO Reduction by Activated Carbons. 1. The Role of Carbon Porosity and Surface Area. Energy and Fuels, 1993, 7 ,

Jin, Y.; Yu, Q.Q.; Chang, S.G. Reduction of Sulfur Dioxide by Syngas to Elemental Sulfur over Iron-based Mixed Oxide Supported Catalyst. Environ. Prog., 1997, 16, 1-8.

Kaneko, K.; Nakahigashi, Y.; Nagata., K. Microporosity and Adsorption characteristics against NO, SO2, and NH3 of Pitch based activated carbon fibres. Carbon, 1988, 26, 327332.

Lu, G.Q.; Do, D.D. Preparation of Economical Sorbents for SO2 and NOx removal from Coal Washery reject. Carbon, 1991, 29, 207-213.

Martin, A.E. "Emission Control Technology for Industrial Boilers." 1981, Noyes Data Corp., Park Ridge, New Jersey, U.S.A.

Pham, E.; Chang, S.G. Removal of NO from Flue Gases by Absorption to an Iron(II) Thiochelate Complex and Subsequent Reduction to Ammonia. Nature 1994, 369, 139141.

Sada, E.; Kumazawa, H.; Kudo, I.; Kondo, T. Individual and Simultaneous Absorption of Dilute NO and SO2 in Aqueous Slurries of MgSO3 with Fe(II)EDTA. Ind. Eng. Chem. Process Res. Dev. 1980, 19, 377-382.

Shi, Y.; Littlejohn, D.; Chang, S.G. Integrated Tests for Removal of Nitric Oxide with Iron Thiochelate in Wet Flue Gas Desulfurization Systems. Environ. Sci. \& Technol. 1996, 30, 3371-3376.

Tsai, S.S.; Bedell, S.A.; Kirby, L.H.; Zabick, D.J. Field Evaluation of Nitric Oxide Abatement with Ferrous Chelates. Environ. Prog. 1989, 8, 126-129.

Tsuji, K.; Shiraishi, I. Mitsui-BF Dry Desulfurization and Denitrification Process Using Activated Coke, Vol 3 , pp. 307-324, $\mathrm{SO}_{2}$ Control Symposium, Sponsored by ERPI, EPA, and DOE, Washington, D. C., December 3-6, 1991. 
Yu, J.J.; Yu, Q.Q.; Jin, Y.; Chang, S.G. Reduction of Sulfur Dioxide by Methane over Supported Cobalt Catalysts. Ind. \& Eng. Chem. Res. 1997, 36, 2128-2133.

Yougen, K.; Cha, C.Y. Reduction of NOx adsorbed on Char with Microwave energy. Carbon, 1996, 34, 1034. 


\section{Figure Captions}

Figure 1. Schematic diagram of the experimental set-up used for the preparation of the activated carbon, adsorption, and reduction of NO.

Figure 2. Rice hull burnoff as a function of Pyrolysis and Activation Temperatures (Activation temperature was $50^{\circ} \mathrm{C}$ higher than pyrolysis).

Figure 3. BJH cumulative pore area of activated carbons prepared from coconut shell, peanut shell, wheat straw, and rice hull.

Figure 4. The effect of pyrolysis and activation temperatures on the adsorption of NO; Flue gas composition was $250 \mathrm{ppm} \mathrm{NO}, 5 \% \mathrm{O}_{2}, 10 \% \mathrm{CO}_{2}$, and the balance $\mathrm{N}_{2}$; $\mathrm{W} / \mathrm{F}=8 \mathrm{~g} \cdot \mathrm{min} . / \mathrm{L}$.

Figure 5. The effect of pyrolysis and activation time on the adsorption of NO; Flue gas composition was $250 \mathrm{ppm} \mathrm{NO}, 5 \% \mathrm{O}_{2}, 10 \% \mathrm{CO}_{2}$, and the balance $\mathrm{N}_{2} ; \mathrm{W} / \mathrm{F}=8 \mathrm{~g} . \mathrm{min} . / \mathrm{L}$.

Figure 6. The effect of temperature on NO adsorption by the activated carbon, RH-2-7001-750; Flue gas composition was 250 ppm NO and the balance N2; W/F=15.4g.min./L.

Figure 7. The effect of oxygen on NO adsorption by the activated carbon, RH-2-700-1750; Flue gas composition was $250 \mathrm{ppm} \mathrm{NO}, 10 \% \mathrm{CO}_{2}$, and the balance $\mathrm{N}_{2}$; $\mathrm{W} / \mathrm{F}=15.4 \mathrm{~g} \cdot \mathrm{min} . / \mathrm{L}$.

Figure 8. The effect of water vapor on NO adsorption by the activated carbon, RH-2-7001-750; Flue gas composition was $250 \mathrm{ppm} \mathrm{NO}, 10 \% \mathrm{CO}_{2}, 5 \% \mathrm{O}_{2}$, and the balance $\mathrm{N}_{2}$; $25^{\circ} \mathrm{C}, \mathrm{W} / \mathrm{F}=15.4 \mathrm{~g} . \mathrm{min} . / \mathrm{L}$.

Figure 9. The effect of flow rate on NO adsorption by the activated carbon, RH-2-700-1$750(15.3 \mathrm{~g})$; Flue gas composition was $250 \mathrm{ppm} \mathrm{NO}, 10 \% \mathrm{CO}_{2}, 5 \% \mathrm{O}_{2}, 2 \% \mathrm{H}_{2} \mathrm{O}$, and the balance $\mathrm{N}_{2} ; 25^{\circ} \mathrm{C}$

Figure 10. Fraction of NO desorbed when integrated over temperatures as the temperature of the carbon bed was raised at $40^{\circ} \mathrm{C} / \mathrm{min} . \mathrm{N}_{2}$ was used as carrier gas at 1 L./min. Before the desorption, NO adsorption by the activated carbon had been performed under two different conditions: without and with $2 \%$ water vapor.

Figure 11. The effect of temperature on NO reduction by the activated carbon at various ratios of carbon weight to flue gas flow rate (W/F in g.min/L)

Figure 12. The effect of NO concentration on NO reduction efficiency by the activated carbon at various ratios of carbon weight to flue gas flow rate (W/F in g.min/L). 
Figure 13. The effect of oxygen on SMAC time using the activated carbon, RH-2-700-1750 ; Flue gas composition was $250 \mathrm{ppm} \mathrm{NO}, 10 \% \mathrm{CO}_{2}$, and the balance $\mathrm{N}_{2} ; 25^{\circ} \mathrm{C}$.

Figure 14. The number of regeneration on the SMAC time using the activated carbon, RH-2-700-1-750; adsorption conditions: 250 ppm NO, 10\% $\mathrm{O}_{2}, 10 \% \mathrm{CO}_{2}$, and the balance $\mathrm{N}_{2}$ at $25^{\circ} \mathrm{C}$ with W/F: 30g.min./L; regeneration conditions: $100 \% \mathrm{~N}_{2}$ at $600^{\circ} \mathrm{C}$ for $15 \mathrm{~min}$. 
Figure 1

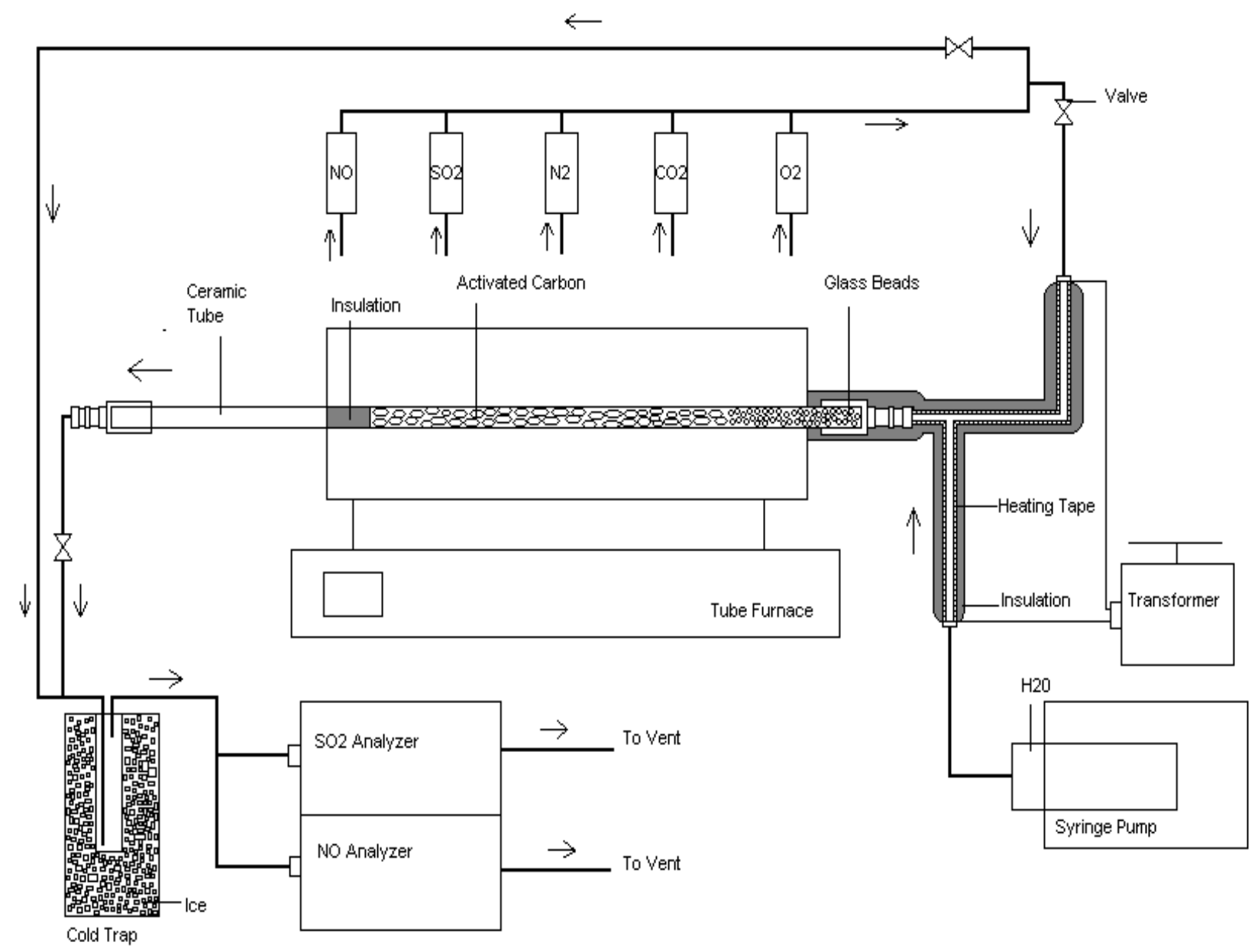


Figure 2

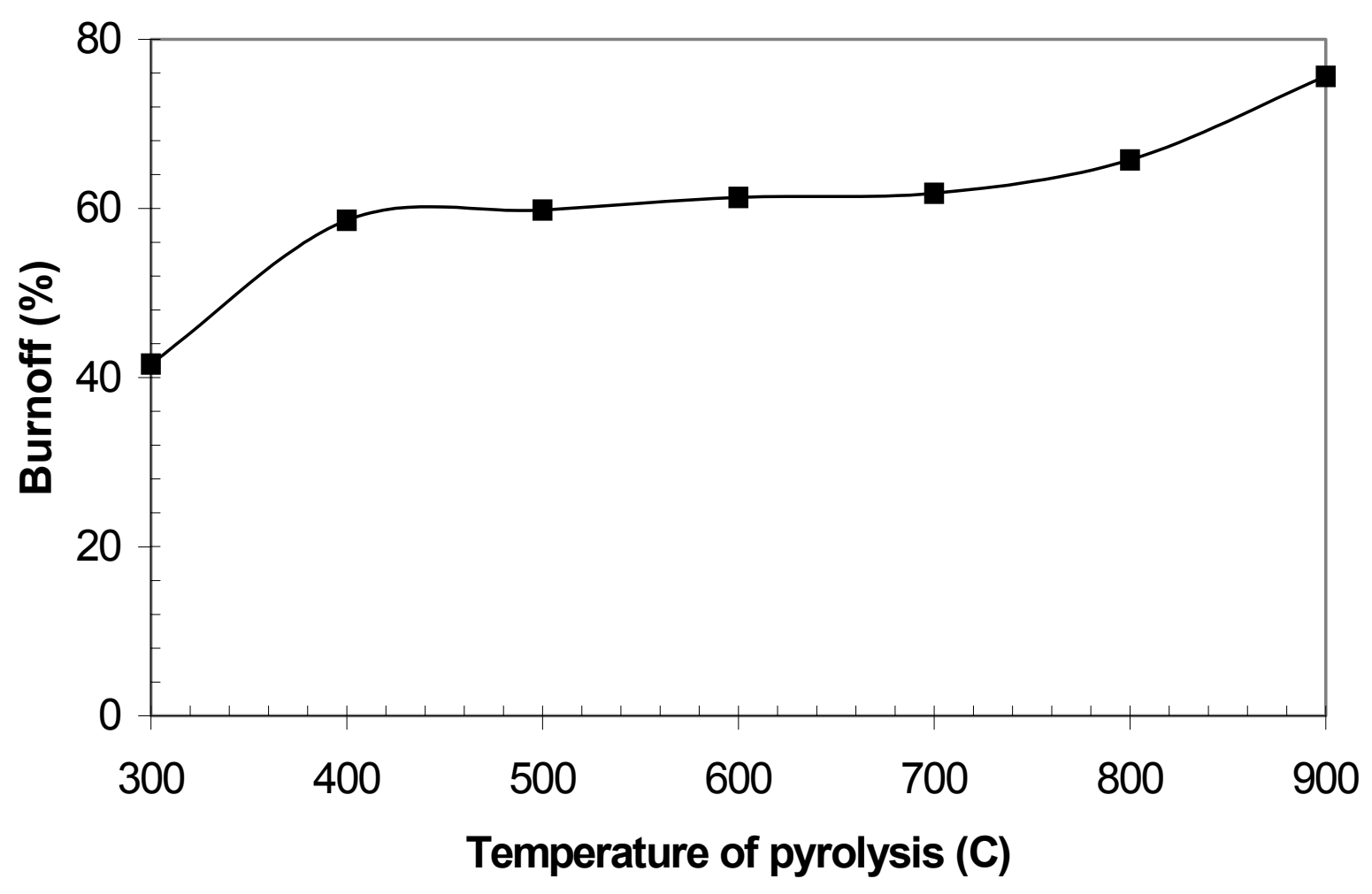


Figure 3

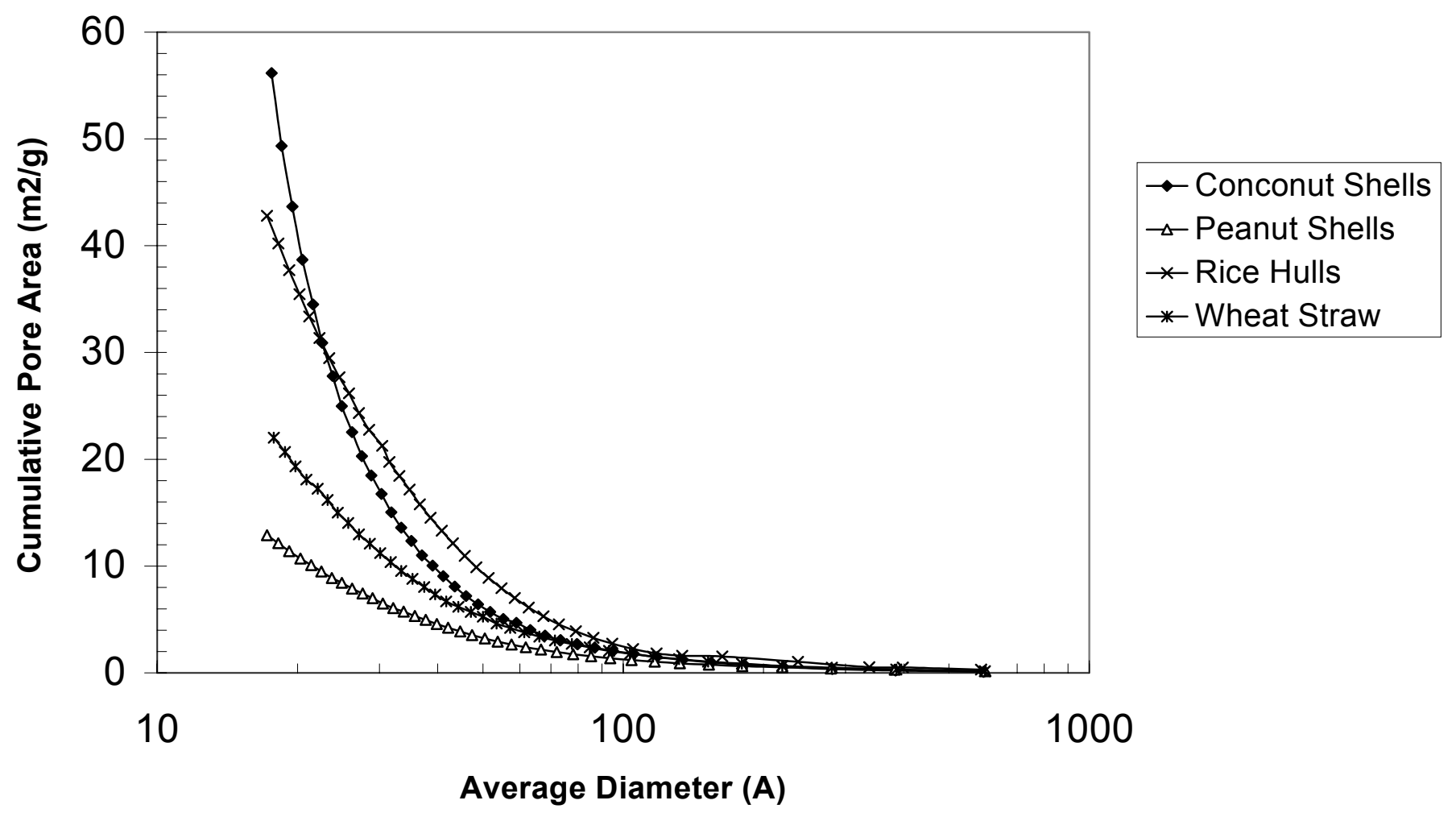


Figure 4

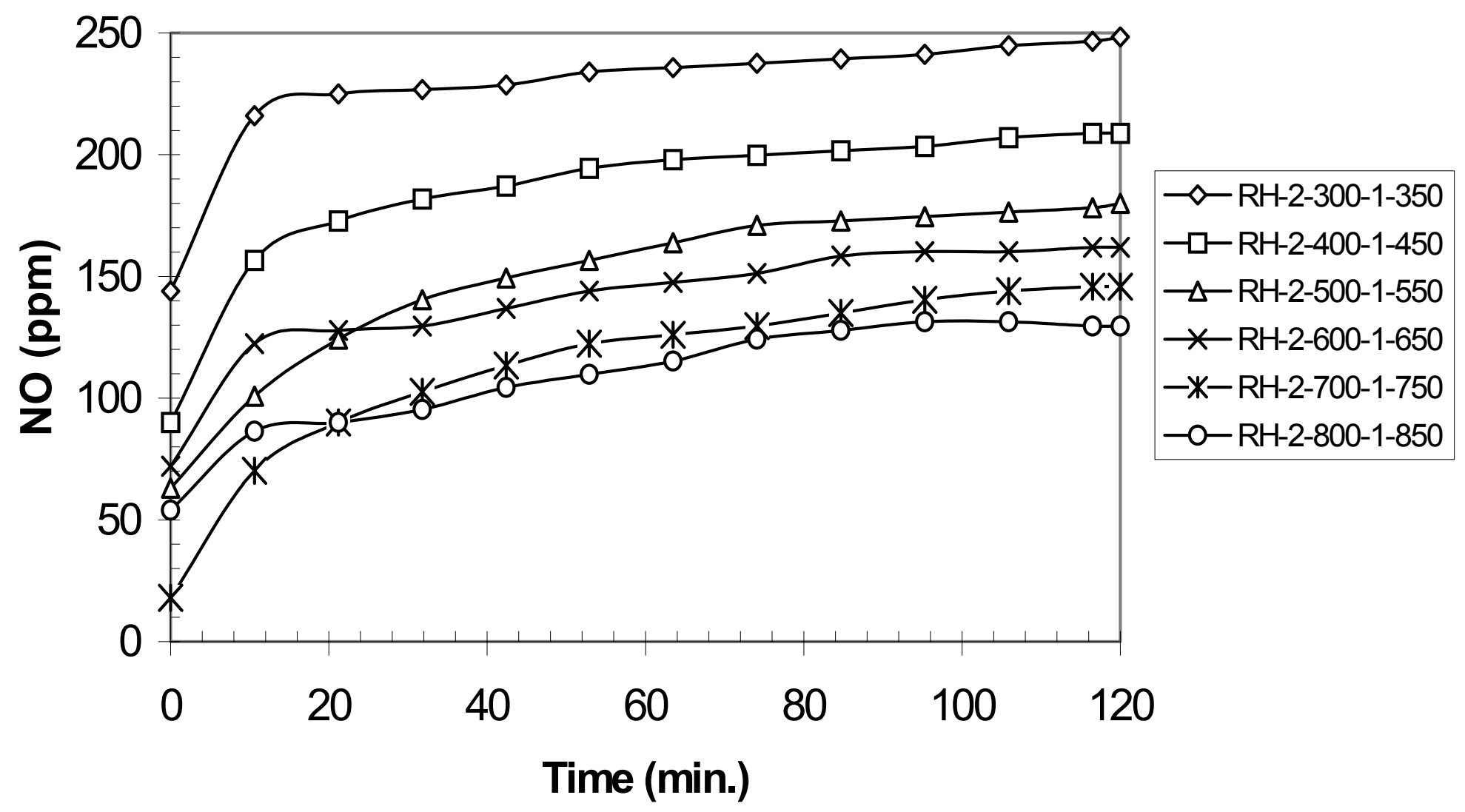


Figure 5

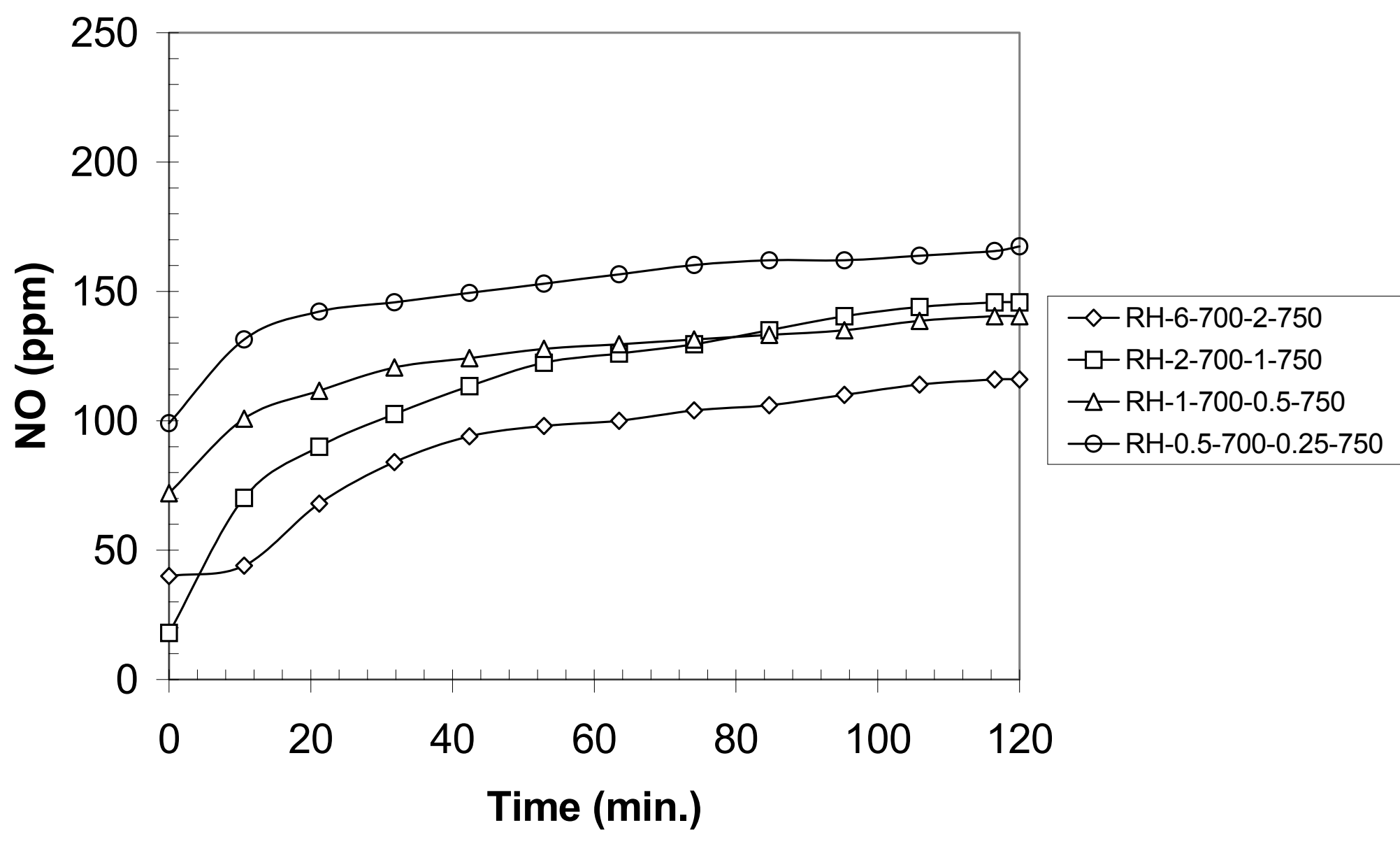


Figure 6

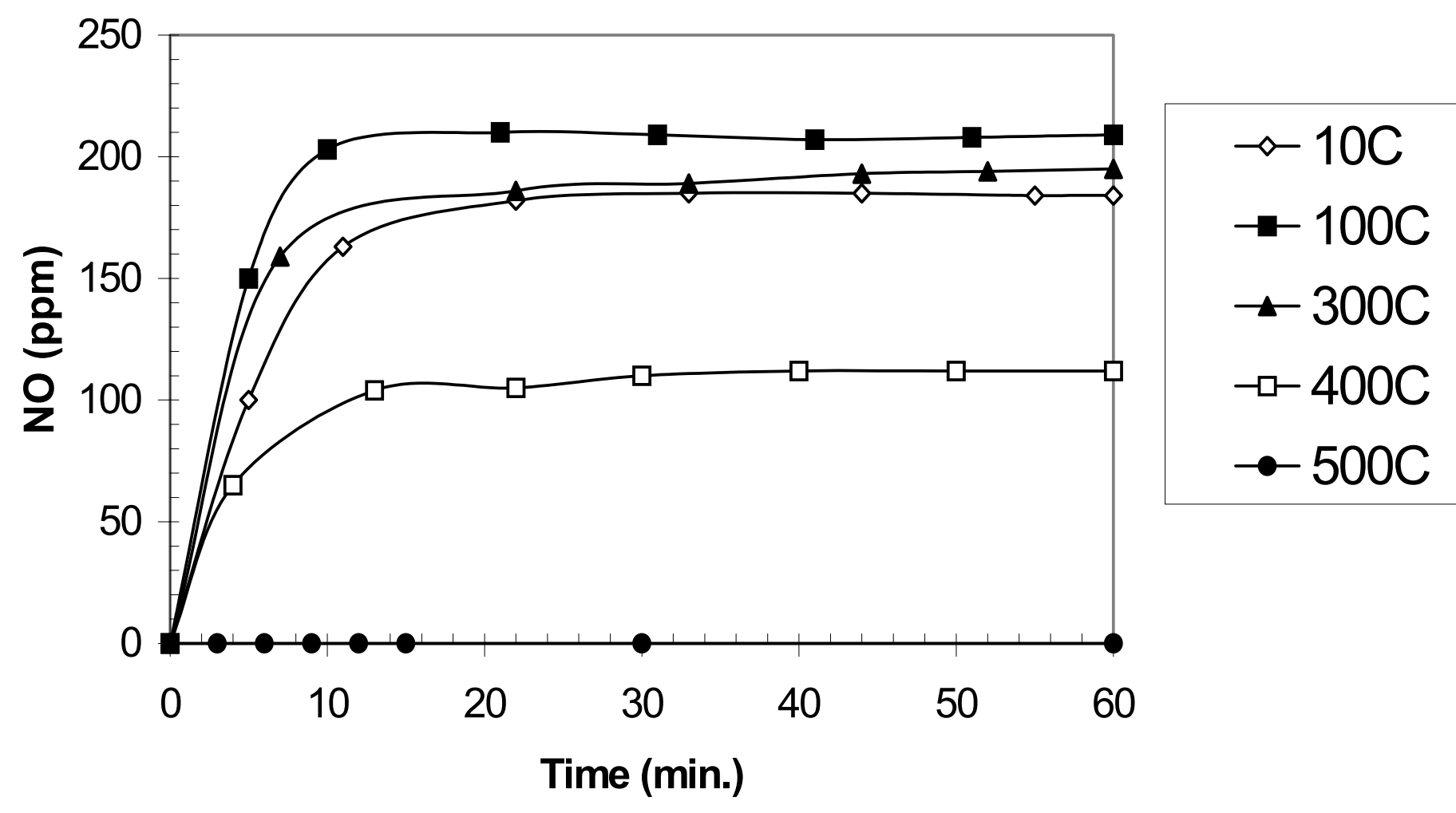


Figure 7

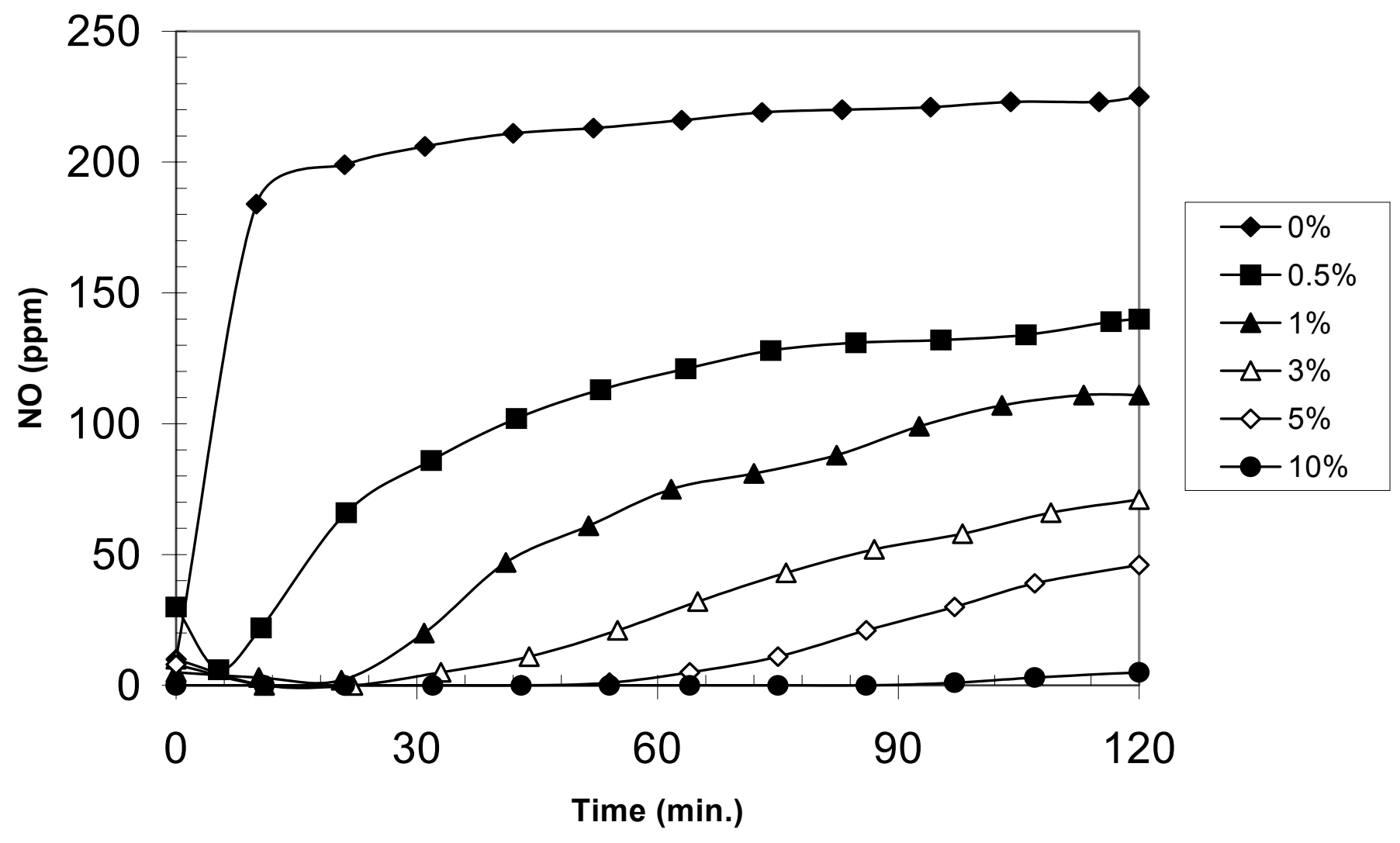


Figure 8

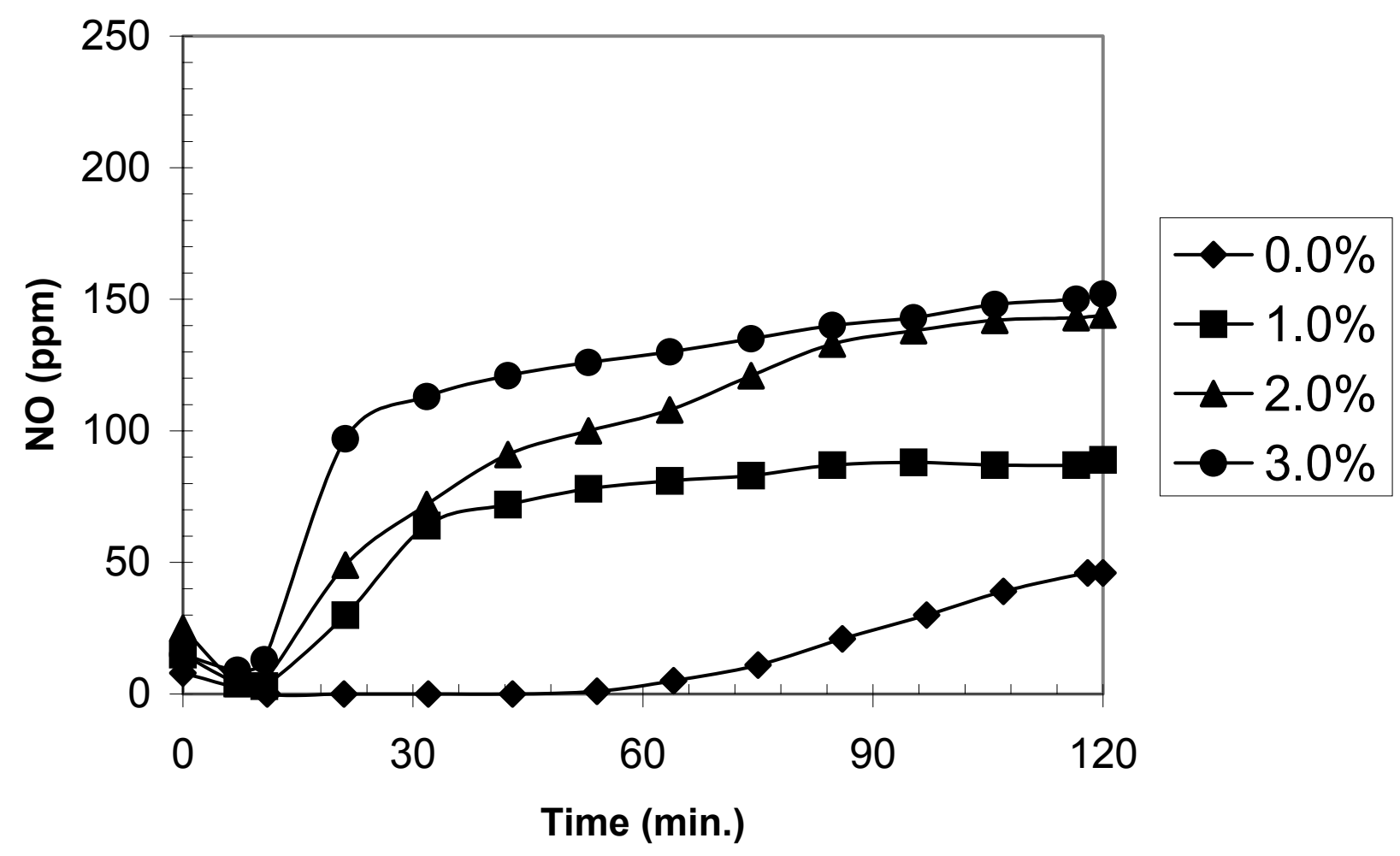


Figure 9

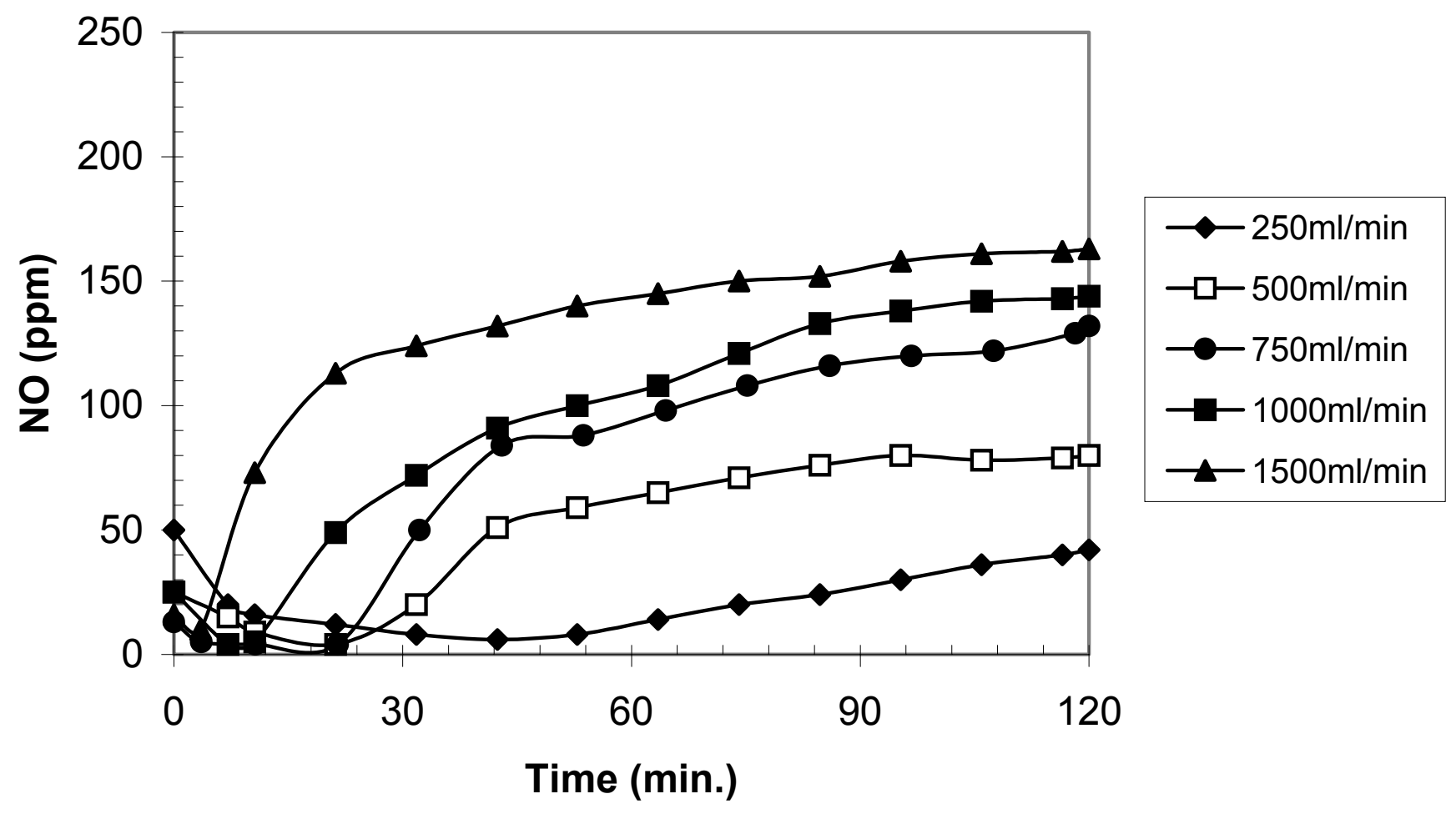


Figure 10

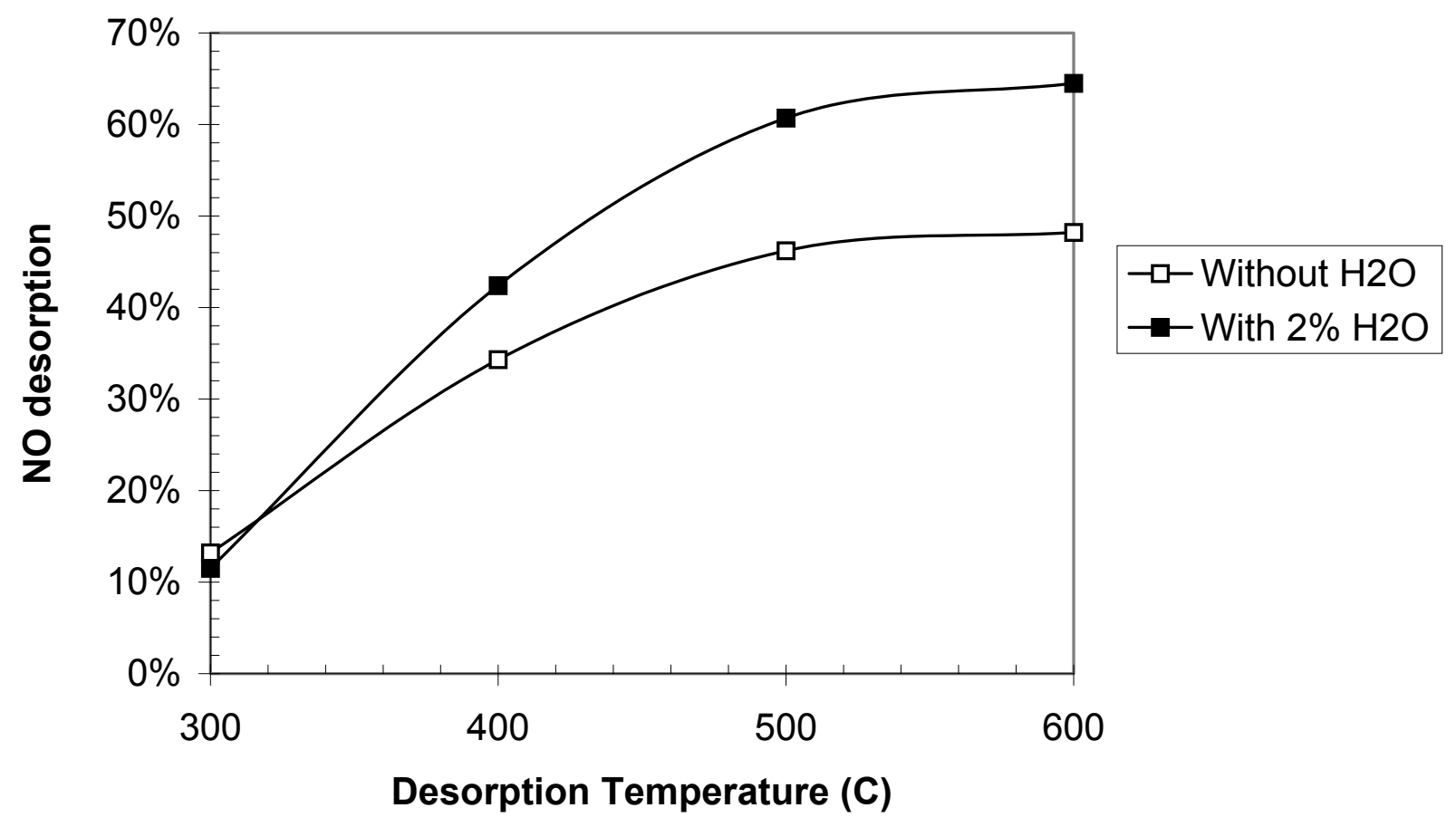


Figure 11

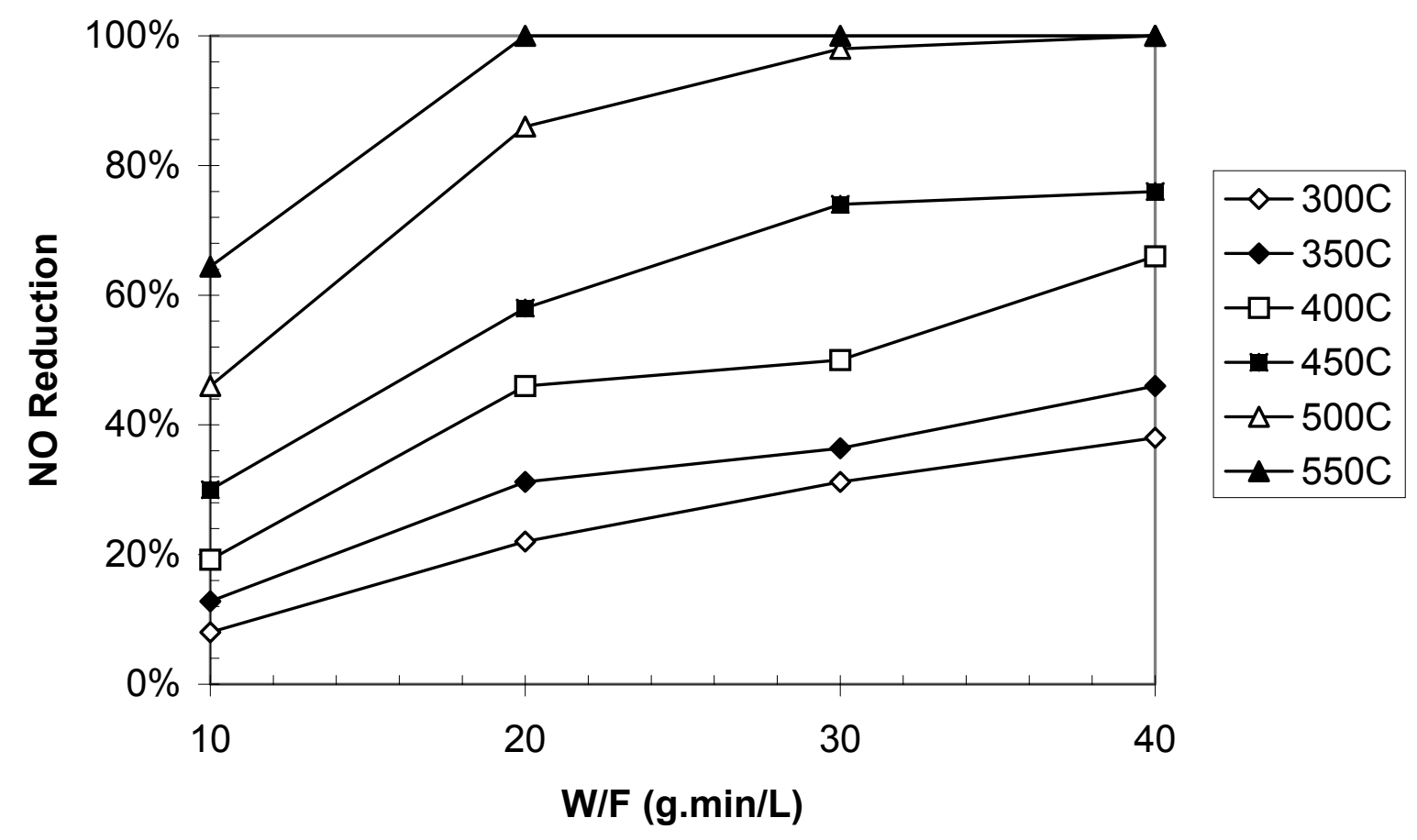


Figure 12

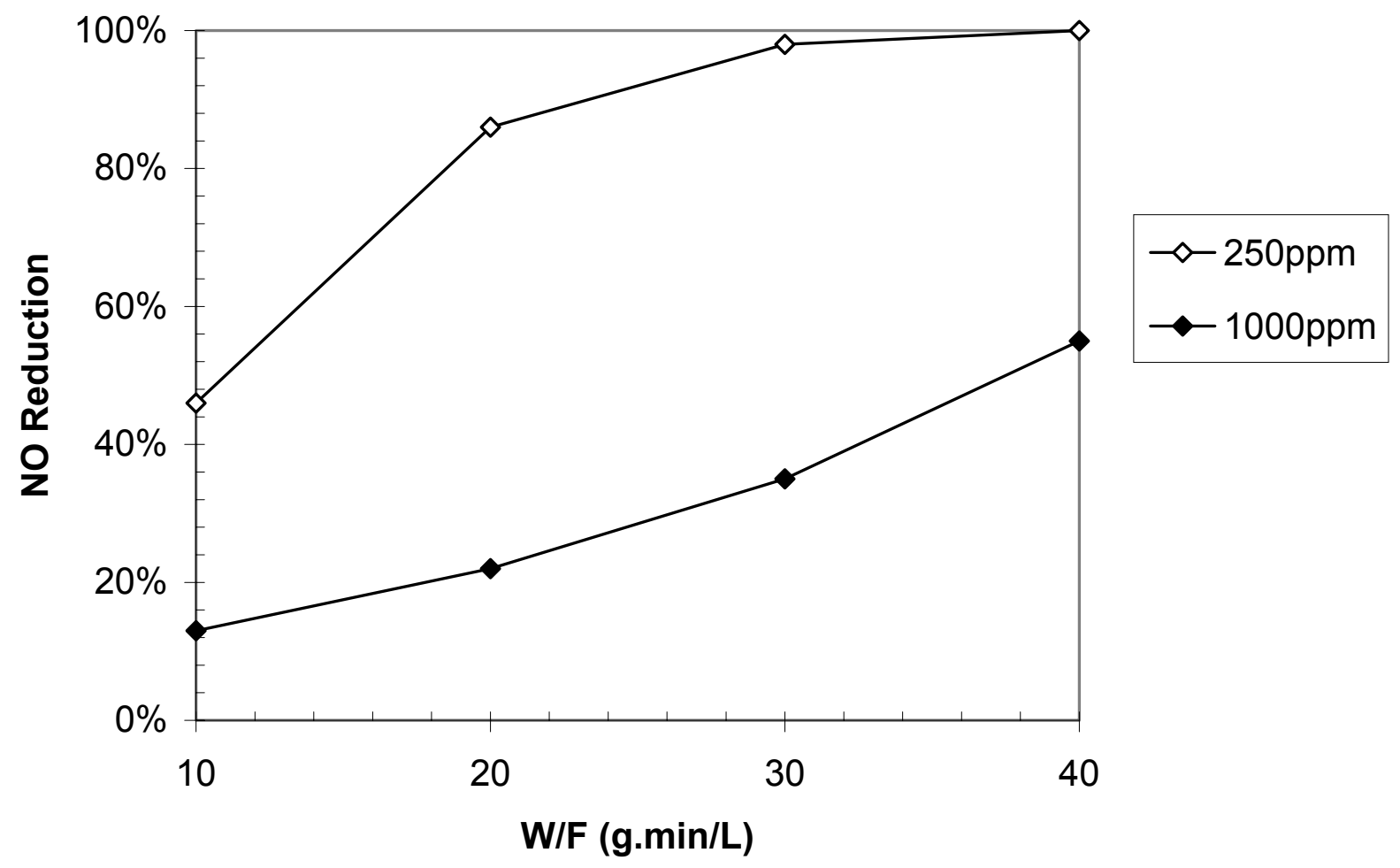


Figure 13

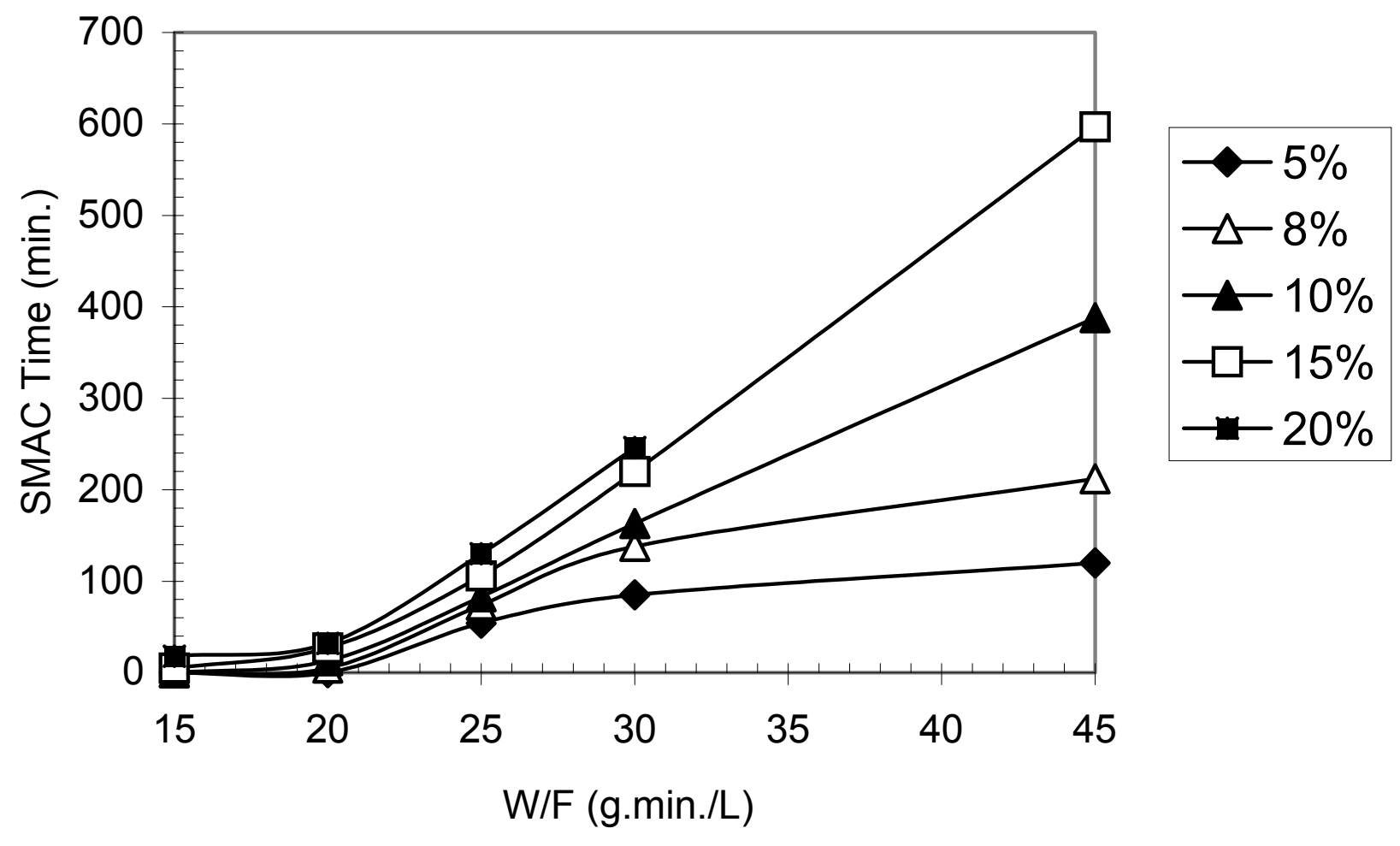


Figure 14

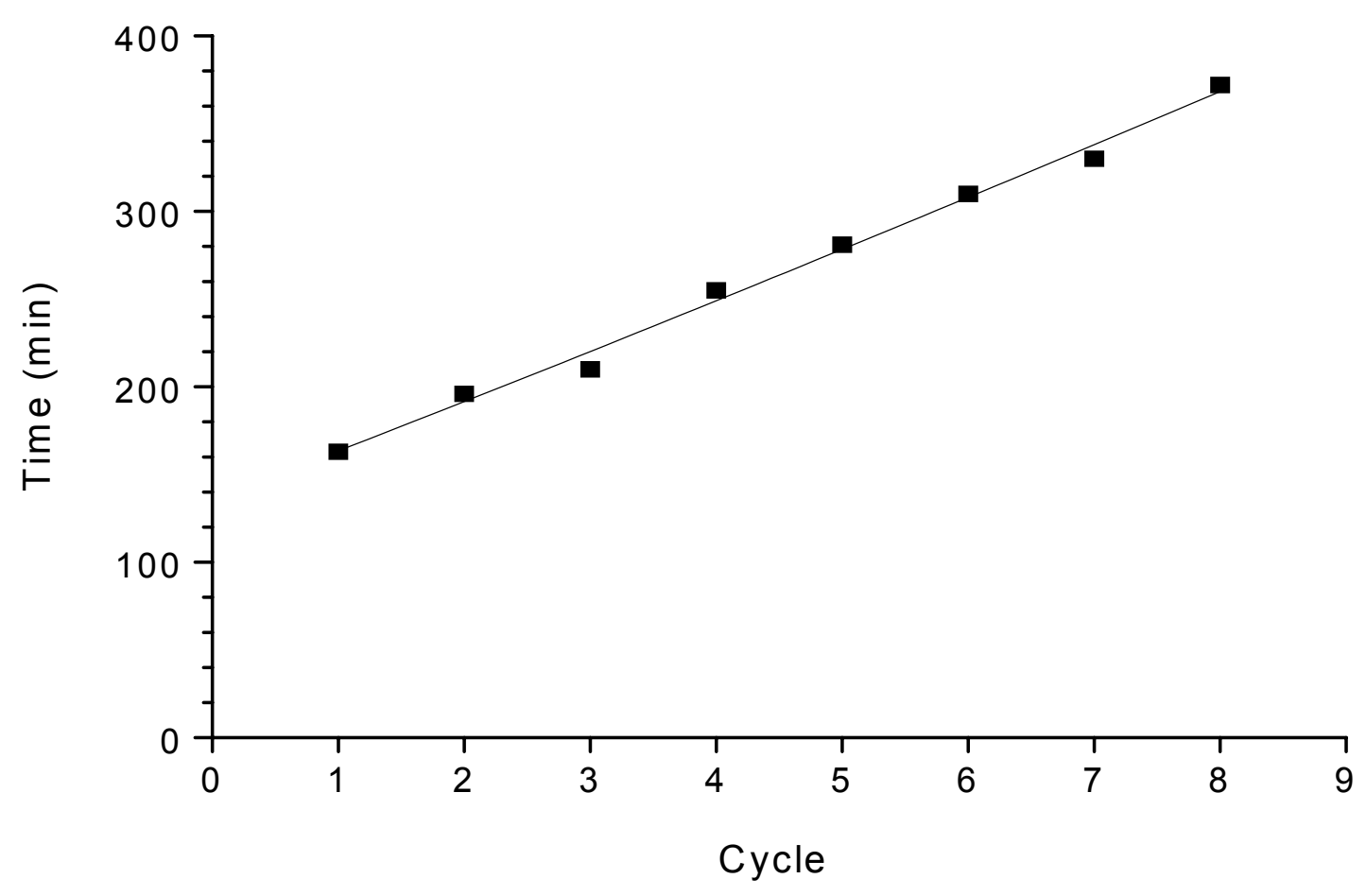

